Article

\title{
Approach to the Dynamic of Carbamazepine and its Main Metabolites in Soil Contamination through the Reuse of Wastewater and Sewage Sludge
}

\author{
José Luis Malvar ${ }^{\mathbb{D}}$, Juan Luis Santos, Julia Martín, Irene Aparicio and Esteban Alonso *(D) \\ Departamento de Química Analítica, Escuela Politécnica Superior, Universidad de Sevilla. C/ Virgen de África, 7, \\ E-41011 Seville, Spain; jmalvar@us.es (J.L.M.); jlsantos@us.es (J.L.S.); jbueno@us.es (J.M.); iaparicio@us.es (I.A.) \\ * Correspondence: ealonso@us.es; Tel.: +34-954-55-62-50
}

Received: 23 September 2020; Accepted: 9 November 2020; Published: 13 November 2020

\begin{abstract}
The release of pharmaceutically active compounds to the soils through the application of sewage sludge and the irrigation with wastewater, or even with surface water, is constant. The adsorption of these compounds onto the soil is one of the key factors affecting their fate in the environment and their potential environmental risks. In this work, the adsorption of carbamazepine (CBZ) and its metabolites, 3-hydroxy-carbamazepine (3OH-CBZ), carbamazepine-10,11-dihydro-10,11-epoxide (EP-CBZ), and 10,11-dihydro-10-hydroxycarbamazepine $(10 \mathrm{OH}-\mathrm{CBZ})$, in three Mediterranean soils was evaluated using single-solute and four-solute experiments. The highest adsorptions were measured for $3 \mathrm{OH}-\mathrm{CBZ}$, followed by CBZ, EP-CBZ, and $10 \mathrm{OH}-\mathrm{CBZ}$, in that order. A high influence of the physicochemical characteristics of the compounds, $\mathrm{pH}$, and soil characteristics in the adsorption of the studied compounds was observed and corroborated by the statistical analysis of the results. Moreover, a good fit was observed in the three isotherm models evaluated (linear, Freundlich, and Langmuir) in single-solute experiments $\left(R^{2}>0.90\right)$. However, a decrease of the measured adsorptions and a worse fit to the isotherm models were observed in the case of multiple-solute experiments. This could be mainly due to the competition established between the studied compounds for the active sites of the soils.
\end{abstract}

Keywords: carbamazepine; metabolites; soil; wastewater; sewage sludge; competitive adsorption

\section{Introduction}

Pharmaceutically active compounds (PhCs) are continuously released into the environment. Their presence in several environmental compartments as wastewater [1-3], surface water [1,4] or sewage sludge [5-7], and soil [5] has been widely documented. Many of these compounds enter into the soil due to irrigation with treated wastewater [8] or through sewage sludge applied to the agricultural soils as organic amendment [9]. The adsorption of PhCs into the soil is one of the main processes governing not only the fate of these compounds in the terrestrial compartment but also their environmental risks, since it determines their availability for plants and other terrestrial organisms.

This adsorption depends on the physicochemical characteristics of the PhCs (water solubility, pKa, molecular size, etc.), environment ( $\mathrm{pH}$, temperature, ionic strength) and soil (texture, organic matter). Recent studies have evaluated the adsorption onto the soil of PhCs as atenolol [10], carbamazepine [10, 11], diclofenac [11,12], trimethoprim [10] or sulfamethoxazole [10]. These studies have shown the influence of the physicochemical characteristics of the pharmaceutical $[10,11]$ or environmental conditions [11] in their adsorption behaviour. However, despite the complexity of environmental systems, most of these studies have been carried out using single-solute experiments. Only a few studies have evaluated the potential interactions or competition between PhCs using sorption experiments. 
Most of these studies were carried out using adsorbent materials such as biochars [13], carbon nanotubes [14] or clay materials [15,16] and, to a less extent, soil [10]. However, there are no studies reporting the potential interaction and competition between $\mathrm{PhCs}$ and their metabolites in soils. However, these metabolites are excreted together with the PhCs, in higher quantities than their parent compounds and even can show higher environmental risks [17-20]. This shows the importance of evaluating the sorption behaviour of these compounds on the soil in multiple-solute systems instead of single-solute systems, as a previous step to the evaluation of this sorption in real systems as wastewater-soil or sludge-soil systems.

Carbamazepine (CBZ) is one of the most prescribed PhCs in the world. It is used to treat epilepsy episodes, bipolar disorder, dysphonia or neuropathic pain [20]. CBZ is mainly excreted by urine ( $72 \%$ of the total of the CBZ consumed), whereas the rest is excreted through feces. The $13 \%$ of the CBZ excreted by feces is as parent compounds whereas, in urine, only $1 \%$ is excreted unchanged [21]. Until now, more than 30 metabolites have been identified. The main metabolic route comprises the epoxidation of CBZ to carbamazepine-10,11-dihydro-10,11-epoxide (EP-CBZ), followed by conversion to 10,11-dihydro-10-hydroxycarbamazepine (10OH-CBZ) [17]. Additionally, phenolic metabolites such as 1-hydroxy carbamazepine (1-OH CBZ), 2-hydroxy carbamazepine (2-OH CBZ) or 3-hydroxy-carbamazepine (3OH-CBZ) have also been formed in a wide proportion [21]. Only a few works have been reported in the recent literature about the behaviour of CBZ and its metabolites in soil $[17,20,22,23]$. These studies have been focused on the determination of the adsorption isotherms of the individual compounds. For this purpose, batch experiments are carried out, in most cases, using reference soils. To the best of our knowledge, there are no studies evaluating the adsorption of CBZ and its main metabolites in multiple-solute experiments in which the competition of the compounds for the adsorption onto the soil could occur.

The aims of this work were (I) to evaluate the adsorption of CBZ and its main metabolites, $3 \mathrm{OH}-\mathrm{CBZ}$, $10 \mathrm{OH}-\mathrm{CBZ}$ and EP-CBZ, in three Mediterranean soil using single-solute and four-solute experiments; (II) to assess the influence of physicochemical characteristics of the compounds, environment and soil in their sorption onto the soils; and (III) to evaluate the competition between studied compounds for their adsorption onto the soils.

\section{Results and Discussion}

\subsection{Preliminary Experiments}

Results obtained in batch experiments for the evaluation of the adsorption equilibrium time are presented in Figure S1 (Supplementary Materials). Adsorption values were approximately constant for $24 \mathrm{~h}$ for all compounds. Consequently, this time was selected for the subsequent experiments. Regarding the soil/solution ratio (Figure S2), the data obtained for 10OH-CBZ and EP-CBZ did not show significant adsorption variations with the increase of the amount of soil. Only a slight increase of their adsorption was observed. By contrast, $\mathrm{CBZ}$ and $3 \mathrm{OH}-\mathrm{CBZ}$ exhibited a great dependency with the amount of soil used. Their adsorption increases with the increase of the ratio soil/solution. This behaviour could be due to the increase of soil active sites at higher soil amount that was observed in major extension for those compounds showing the higher adsorption. For this reason, the highest ratio $(5: 10(w / v))$ was selected as the optimal ratio.

\subsection{Adsorption of Studied Compounds}

\subsubsection{Single-Solute Systems}

In all studied soils, the adsorption capacity follows the same order: $3 \mathrm{OH}-\mathrm{CBZ}>\mathrm{CBZ}>\mathrm{EP}-\mathrm{CBZ}>$ 10OH-CBZ (Figure 1). This distribution was similar to those measured by other authors $[17,23]$ and could be explained considering the molecular structure of studied compounds. 

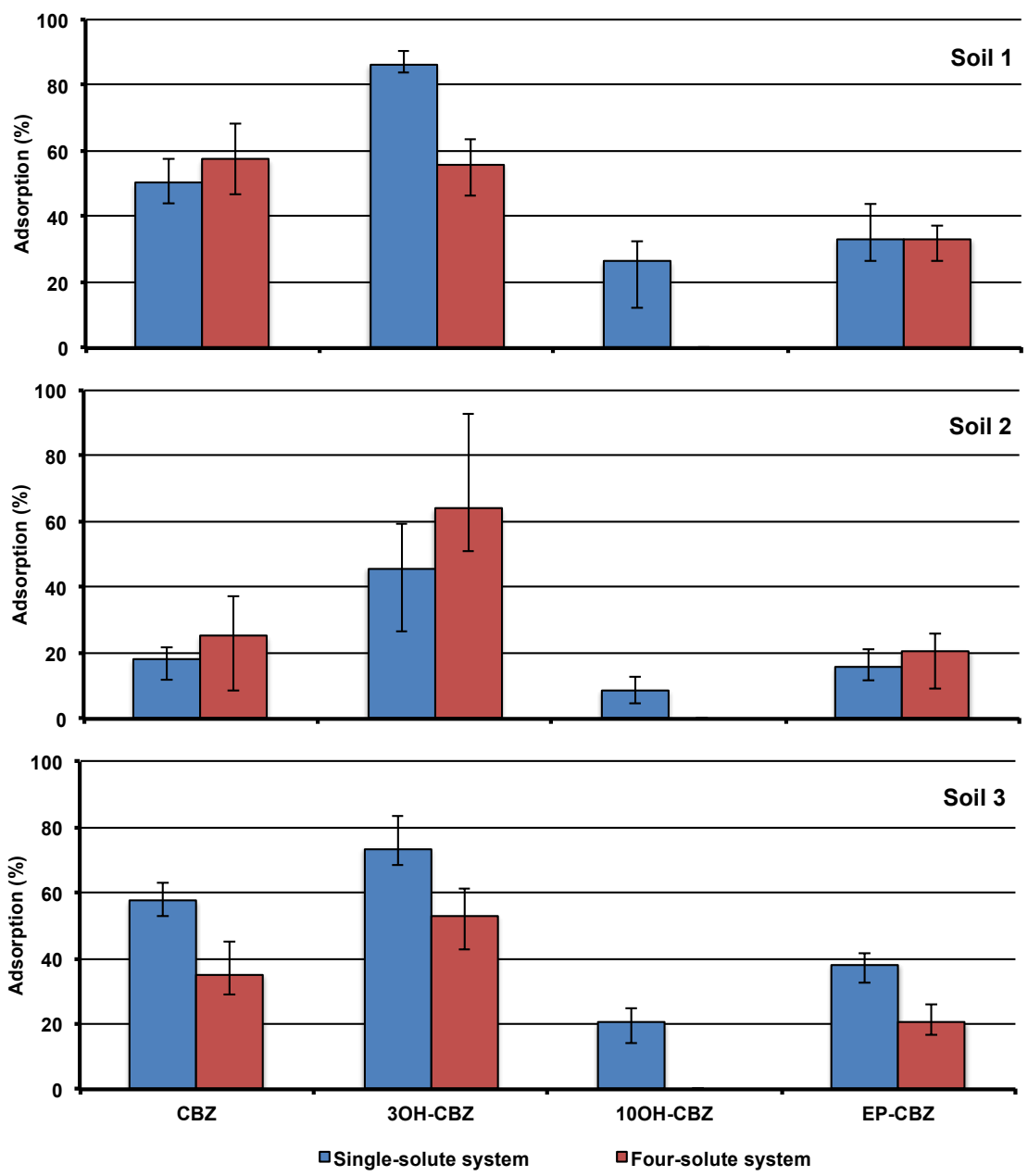

Figure 1. Adsorption of carbamazepine (CBZ) and its main metabolites, 3-hydroxy-carbamazepine (3OH-CBZ), carbamazepine-10,11-dihydro-10,11-epoxide (EP-CBZ), and 10,11-dihydro-10-hydroxycarbamazepine (10OH-CBZ) in the studied soil in single-solute system and in four-solute system.

For example, Paz et al. (2016) [23] related the different adsorptions of CBZ, EP-CBZ, and 10,11-dihydro-10,11-dihydroxycarbamazepine (DiOH-CBZ) with their heterogeneous charge distribution density. The electronegative oxygen atoms sited in the epoxide- and hydroxyl groups of the EP-CBZ and 10OH-CBZ, respectively, allow them to form hydrogen bonds with water molecules. These interactions can inhibit their adsorption onto the soil surface [23]. This would explain the low affinity of $10 \mathrm{OH}-\mathrm{CBZ}$ for the studied soils. The high affinity of $3 \mathrm{OH}-\mathrm{CBZ}$ could be explained by the position of the hydroxide group, sited near to the amino group. This hydroxide group can contribute to enhanced stability of the molecule on the soil surface due to the formation of hydrogen bonds with the functional groups of the soil organic matter, as it has been described for other compounds [23].

Considering the influence of $\mathrm{pH}$ on the adsorption, no significant differences were observed for EP-CBZ in soil 1 (adsorptions measured were from 25 to 32\%, standard deviation $2.8 \%$ ) and soil 3 (from 27 to 33\%, standard deviation 2.3\%) at different $\mathrm{pH}$ values (Figure S3). In the case of CBZ and $10 \mathrm{OH}-\mathrm{CBZ}$, a slight decrease of their adsorption was measured as $\mathrm{pH}$ grows from 2 to 12 . In the case of $3 \mathrm{OH}-\mathrm{CBZ}$, a strong influence of $\mathrm{pH}$ was observed. Mean adsorption of $3 \mathrm{OH}-\mathrm{CBZ}$ measured between $\mathrm{pH} 2$ and 10 was $56.0 \pm 1.7$ and $51.5 \pm 1.5 \%$ for soils 1 and 3 , respectively, while the adsorption measured at $\mathrm{pH} 12$ was $23 \pm 3.0 \%$ for soil 1 and $6.07 \pm 0.14 \%$ in the case of soil 3 . These results could be explained considering the $\mathrm{pK}_{\mathrm{a}}$ value of the studied compounds. EP-CBZ $\left(\mathrm{pK}_{\mathrm{a}}=16.0\right)$ was not affected by the $\mathrm{pH}$ between 2 and 12. The compounds $\mathrm{CBZ}$ and $10 \mathrm{OH}-\mathrm{CBZ}\left(\mathrm{pK}_{\mathrm{a}} 12.8\right.$ and 13.9, respectively) are 
partially deprotonated at $\mathrm{pH} 12$. At this $\mathrm{pH}$ value, the adsorption could be inhibited by electrostatic repulsion between the ionic form of the compounds and the soil surface; consequently, the ionic forms showed higher affinity by the liquid phase. This was particularly observed on $3 \mathrm{OH}-\mathrm{CBZ}\left(\mathrm{pK}_{\mathrm{a}}=9.19\right)$, which is in its ionic form at $\mathrm{pH} 12$.

Soil 2 showed the lowest adsorption capacity, followed by soil 1 and soil 3, in that order. This could be related to the high amount of sand $(74 \%)$ and low organic matter $(0.58 \%)$ of the soil 2 , which facilities the permeability and leaching of these pollutants as it was described previously $[10,17,23,24]$. In the case of soil 1 ( $24.6 \%$ of sand and $0.91 \%$ of organic matter), the adsorptions measured were in the ranges $84-90 \%, 44-58 \%, 27-44 \%$, and $12-33 \%$ for $3 \mathrm{OH}-\mathrm{CBZ}, \mathrm{CBZ}, \mathrm{EP}-\mathrm{CBZ}$ and $10 \mathrm{OH}-\mathrm{CBZ}$, respectively. For soil 3 (65.6\% of sand and $2.01 \%$ of organic matter), the same order was observed: $3 \mathrm{OH}-\mathrm{CBZ}(68-83 \%)>$ CBZ $(53-63 \%)>$ EP-CBZ $(32-42 \%)>10 \mathrm{OH}-\mathrm{CBZ}(14-25 \%)$. As can be seen, soils 1 and 3 showed similar adsorption capacity of each of the studied compounds, except in the case of $3 \mathrm{OH}-\mathrm{CBZ}$, which showed significant differences (Student $t$-test: $t_{\mathrm{cal}}=4.727, \mathrm{t}_{\mathrm{tab}}=2.228, p>0.05$ ). The influence of soil characteristics in the adsorption of the studied compounds was corroborated by the statistical multifactorial analysis. The correlation matrix obtained in the single-solute experiments is shown in Table S1 (supplementary material). High correlations (absolute value higher than 0.70) were obtained between the adsorptions of the compounds with hydroxide groups (3OH-CBZ and $10 \mathrm{OH}-\mathrm{CBZ}$ ) and the silt and clay content of the soil. Moreover, high correlations were obtained between the adsorptions of compounds without hydroxide groups (CBZ and EP-CBZ) with the organic matter. Considering factor analysis, two factors, with eigenvalues higher than 1 (Factor 1: 5.56; Factor 2: 4.44), were obtained using the data obtained in the single-solute experiments (Table S2). These factors could indicate different adsorption mechanics of the compounds depending on their functional groups and the influence of the physicochemical characteristics of the soil on these mechanics. The first factor, accounting for $56 \%$ of the total variability, was composed of $3 \mathrm{OH}-\mathrm{CBZ}$ and $10 \mathrm{OH}-\mathrm{CBZ}$ and the texture (sand, silt, and clay content) of the soil. The second factor, accounting for $44 \%$ of the total variability, was composed of $\mathrm{CBZ}$ and EP-CBZ and the organic matter contents. This indicates a higher interaction of polar compounds ( $3 \mathrm{OH}-\mathrm{CBZ}$ and $10 \mathrm{OH}-\mathrm{CBZ}$ ) with silt and clay and a higher interaction of non-polar compound (CBZ and EP-CBZ) with organic matter of the soil.

\subsubsection{Four-Solute Systems}

Significant differences were not observed between adsorptions measured in soil 2 for the four-solute systems (Figure 1) with those measured in the single-solute systems. In the case of soil 1, a significant reduction of the adsorption was measured for $3 \mathrm{OH}-\mathrm{CBZ}$ (Student $\mathrm{t}$-test: $\mathrm{t}_{\mathrm{cal}}=12.0, \mathrm{t}_{\mathrm{tab}}=2.28, p<$ 0.05 ) and $10 \mathrm{OH}-\mathrm{CBZ}$ (from $26.4 \%$ in the case of single-solute experiments to no adsorption in the case of four solute experiments). Considering soil 3, all studied compounds showed lower adsorptions in the four-solute experiments (Student $t$-test CBZ: $\mathrm{t}_{\mathrm{cal}}=5.167, \mathrm{t}_{\mathrm{tab}}=2.571, p>0.05$; 3OH-CBZ: $\left.\mathrm{t}_{\mathrm{cal}}=5.670, \mathrm{t}_{\mathrm{tab}}=2.228, p<0.05 ; \mathrm{EP}-\mathrm{CBZ}: \mathrm{t}_{\mathrm{cal}}=7.825, \mathrm{t}_{\mathrm{tab}}=2.228, p<0.05\right)$. These results could be due to the competition of the studied compounds for their adsorption onto the soils in the four-solute system. This was especially important in the case of soil 3. The multivariable analysis showed relations between the adsorption of CBZ and its metabolites and the texture of the soils (Table S1). Positive correlations were obtained between the adsorptions and silt and clay, and negatives with coarse sand. Moreover, in contrast with the single-solute experiments, correlations between adsorptions and organic matter were not observed. These results indicate a low influence of the organic matter in the adsorption of CBZ and its metabolites, which is contrary to the results obtained in the single-solute experiments. The same results were obtained in the factorial analysis. Two factors, with eigenvalues higher than 1 (Factor 1: 6.05; Factor 2: 2.95), were obtained (Table S3). The first factor, accounting for $67 \%$ of the total variability, was composed of the studied compounds and the texture parameters. The second factor, accounting for $33 \%$ of the total variability, was composed only of the organic matter. These results show that in multiple-solute systems the silt and clay content of the soil could play a more important role than organic matter on the adsorption of organic pollutants onto the soil. 


\subsection{Adsorption Isotherms}

\subsubsection{Single-Solute Systems}

Adsorption curves of CBZ and its metabolites in the single-solute systems are shown in Figure 2. In all cases, an increase of the adsorbed amount was observed with the increase of the initial concentration. Moreover, graphically, the saturation of the soils was not observed, except in the case of $10 \mathrm{OH}-\mathrm{CBZ}$ in soil 1. This could be due to the low concentration range evaluated in this work. Similar results have been obtained in other studies carried out at concentrations up to $10 \mu \mathrm{g} \mathrm{mL} \mathrm{m}^{-1}[10,17,20]$.
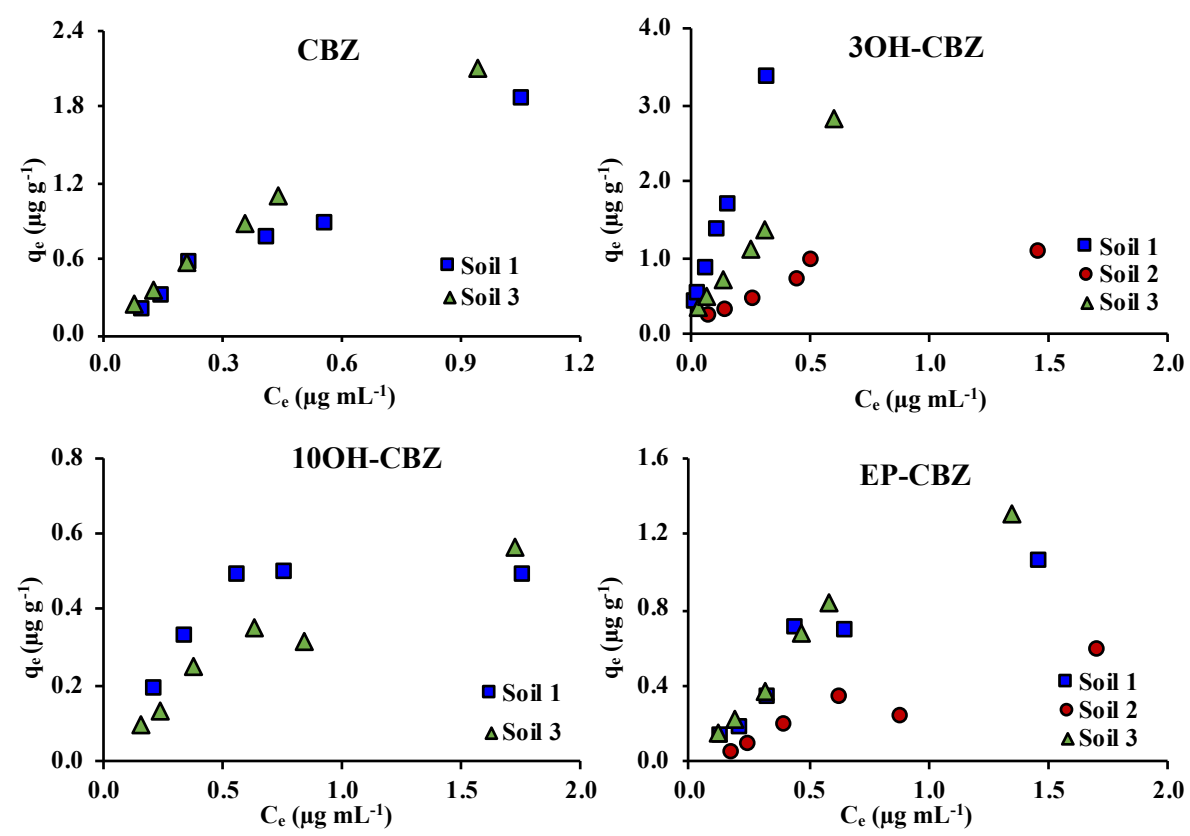

Figure 2. Adsorption curves for CBZ and its metabolites in studied soils in the single-solute systems; $\mathrm{q}_{\mathrm{e}}$ : amount of compound adsorbed; $\mathrm{C}_{\mathrm{e}}$ : concentration of compound in the equilibrium solution.

Linear, Freundlich and Langmuir isotherms obtained in the single-solute experiments are shown in Figures S4-S13 (Supplementary Materials). Table 1 shows the parameters calculated for each of the studied adsorption models. In general, good fitting $\left(\mathrm{R}^{2}>0.90\right)$ was obtained in the most cases for all evaluated models. EP-CBZ showed $\mathrm{R}^{2}$ values slightly lower than 0.9 . Low correlation coefficients were obtained only in the case of $10 \mathrm{OH}-\mathrm{CBZ}$ in soil 1 for linear (0.4142) and Freundlich (0.6911) models. The good fitting obtained, especially in the case of the linear model, has been described as indicative of the interaction of hydrophobic compounds and the soil organic matter [25]. This could corroborate the influence of organic matter on the adsorption of the studied compounds onto the soil.

Considering the water/soil partition coefficient $\left(\mathrm{K}_{\mathrm{d}}\right)$, the lineal correlation obtained could imply a constant availability of the active sites at the evaluated concentrations [26]. The obtained $\mathrm{K}_{\mathrm{d}}$ values were similar to those previously reported $[17,20,23]$. The highest $\mathrm{K}_{\mathrm{d}}$ values were obtained for $3 \mathrm{OH}-\mathrm{CBZ}$ (9.89, 1.58 and 4.29 in soils 1, 2 and 3, respectively) and CBZ (1.65 and 2.12 in soils 1 and 3, respectively). EP-CBZ (0.68, 0.32 and 0.93 in soils 1, 2 and 3) and 10OH-CBZ (0.14 and 0.28 in soils 1 and 3) showed the lowest $K_{d}$ values. The differences between the $K_{d}$ values of the studied soils show the influence of the physicochemical characteristics of the soils, as it was described previously [20]. These $\mathrm{K}_{\mathrm{d}}$ values show a high mobility of the compounds in the studied soils [27], especially in soil 2. Moreover, negative correlations were observed between $\mathrm{K}_{\mathrm{d}}$ and $\mathrm{pK}_{\mathrm{a}}$ values in the case of soils 1 and 3 (Pearson correlation coefficient of -0.87 and -0.76 were obtained for soils 1 and 3 , respectively). This shows the important influence of the $\mathrm{pH}$ in the adsorption of some of the studied compounds onto the soils as it was described above. 
Table 1. Soil/water partition coefficient $\left(K_{d}\right)$, Freundlich constant $\left(K_{F}\right)$, Freundlich exponent $(1 / n)$, Langmuir constant $\left(\mathrm{K}_{\mathrm{L}}\right)$, and maximal sorption capacity $\left(\mathrm{q}_{\max }\right)$ of $\mathrm{CBZ}$ and its metabolites measured in the studied soils.

\begin{tabular}{|c|c|c|c|c|c|c|c|c|}
\hline & \multicolumn{2}{|c|}{ Henry } & \multicolumn{3}{|c|}{ Freundlich } & \multicolumn{3}{|c|}{ Langmuir } \\
\hline & $\begin{array}{c}K_{d}(m L \\
\left.g^{-1}\right)\end{array}$ & $\mathbf{R}^{2}$ & $\begin{array}{l}K_{F}\left(\left(\mu g g^{-1}\right)\right) \\
\left.\left(m L \mu g^{-1}\right)^{1 / n}\right)\end{array}$ & $1 / n$ & $\mathbf{R}^{2}$ & $\begin{array}{c}\mathrm{K}_{\mathrm{L}}(\mathrm{mL} \\
\left.\mathrm{g}^{-1}\right)\end{array}$ & $\begin{array}{c}q_{\max }(\mu g \\
\left.g^{-1}\right)\end{array}$ & $\mathbf{R}^{2}$ \\
\hline \multicolumn{9}{|c|}{ Single-Solute System } \\
\hline \multicolumn{9}{|c|}{ CBZ } \\
\hline Soil 1 & 1.65 & 0.9783 & 1.69 & 0.848 & 0.9698 & 0.45 & 5.30 & 0.9801 \\
\hline Soil 2 & - & - & - & - & - & - & - & - \\
\hline Soil 3 & 2.12 & 0.9975 & 2.19 & 0.842 & 0.9990 & 1.05 & 3.38 & 0.9914 \\
\hline \multicolumn{9}{|c|}{ 3OH-CBZ } \\
\hline Soil 1 & 9.89 & 0.9974 & 7.12 & 0.762 & 0.9835 & 8.27 & 2.71 & 0.9473 \\
\hline Soil 2 & 1.58 & 0.9906 & 1.52 & 0.803 & 0.9692 & 2.04 & 1.54 & 0.9176 \\
\hline Soil 3 & 4.29 & 0.9895 & 3.31 & 0.709 & 0.9713 & 5.73 & 1.97 & 0.9525 \\
\hline \multicolumn{9}{|c|}{ 10OH-CBZ } \\
\hline Soil 1 & 0.14 & 0.4142 & 0.49 & 0.432 & 0.6911 & 1.27 & 0.98 & 0.9055 \\
\hline Soil 2 & - & - & - & - & - & - & - & - \\
\hline Soil 3 & 0.28 & 0.9225 & 0.41 & 0.723 & 0.9501 & 0.56 & 1.21 & 0.9830 \\
\hline \multicolumn{9}{|c|}{ EP-CBZ } \\
\hline Soil 1 & 0.68 & 0.8432 & 0.94 & 0.953 & 0.9052 & -0.21 & -4.35 & 0.9599 \\
\hline Soil 2 & 0.32 & 0.8879 & 0.37 & 1.005 & 0.8923 & -0.46 & -0.65 & 0.9249 \\
\hline Soil 3 & 0.93 & 0.9353 & 1.16 & 0.934 & 0.9711 & 0.04 & 35.06 & 0.9926 \\
\hline \multicolumn{9}{|c|}{ Four-Solute System } \\
\hline \multicolumn{9}{|c|}{ CBZ } \\
\hline Soil 1 & 1.60 & 0.9732 & 1.82 & 0.713 & 0.9911 & 2.57 & 1.83 & 0.9584 \\
\hline Soil 2 & - & - & - & - & - & - & - & - \\
\hline Soil 3 & 0.83 & 0.9747 & 0.86 & 0.702 & 0.9445 & 0.83 & 1.17 & 0.9287 \\
\hline \multicolumn{9}{|c|}{$3 \mathrm{OH}-\mathrm{CBZ}$} \\
\hline Soil 1 & 1.53 & 0.9679 & 1.71 & 0.646 & 0.9285 & 4.43 & 1.37 & 0.7284 \\
\hline Soil 2 & 2.23 & 0.9405 & 1.45 & 0.387 & 0.7464 & 55.84 & 0.84 & 0.5626 \\
\hline Soil 3 & 1.25 & 0.9461 & 1.64 & 0.695 & 0.9736 & 17.29 & 2.45 & 0.9636 \\
\hline \multicolumn{9}{|c|}{$10 \mathrm{OH}-\mathrm{CBZ}$} \\
\hline Soil 1 & - & - & - & - & - & - & - & - \\
\hline Soil 2 & - & - & - & - & - & - & - & - \\
\hline Soil 3 & - & - & - & - & - & - & - & - \\
\hline \multicolumn{9}{|c|}{ EP-CBZ } \\
\hline Soil 1 & 0.68 & 0.9271 & 0.90 & 0.891 & 0.9680 & 0.08 & 12.57 & 0.9912 \\
\hline Soil 2 & 0.14 & 0.4900 & 0.36 & 0.559 & 0.8074 & 0.84 & 0.80 & 0.9601 \\
\hline Soil 3 & 0.39 & 0.9100 & 0.50 & 0.966 & 0.8947 & -0.52 & -1.18 & 0.9147 \\
\hline
\end{tabular}

Considering the Freundlich model, the parameter 1/n was lower than 1 in all cases, except for EP-CBZ (Table 1). These values indicate a favourable adsorption process [28]. Moreover, $1 / \mathrm{n}$ values were close to 1 in all cases (from 0.709 to 1.005), except for 10OH-CBZ in soil 1. This explains the high correlation coefficients obtained in both linear and Freundlich models since when $1 / n$ is equal to 1 , the Freundlich equation becomes linear. As a result, $\mathrm{K}_{\mathrm{d}}$ and $\mathrm{K}_{\mathrm{F}}$ obtained were similar.

Considering Langmuir model, a good fit was measured for all compounds and soils. However, the highest concentrations applied in this work were not high enough to achieve the soil saturation and, consequently, to evaluate the suitability of this model. Indeed, non-realistic values for $\mathrm{q}_{\max }$ and $\mathrm{k}_{\mathrm{L}}$ were obtained in the case of EP-CBZ (Table 1). 


\subsubsection{Four-Solute Systems}

Adsorption curves of the studied compounds in the soils in the four-solute systems are shown in Figure 3. Adsorption isotherms obtained in four-solute experiments are shown in Figures S4-S13. The parameters calculated for each of the studied adsorption models are shown in Table 1.
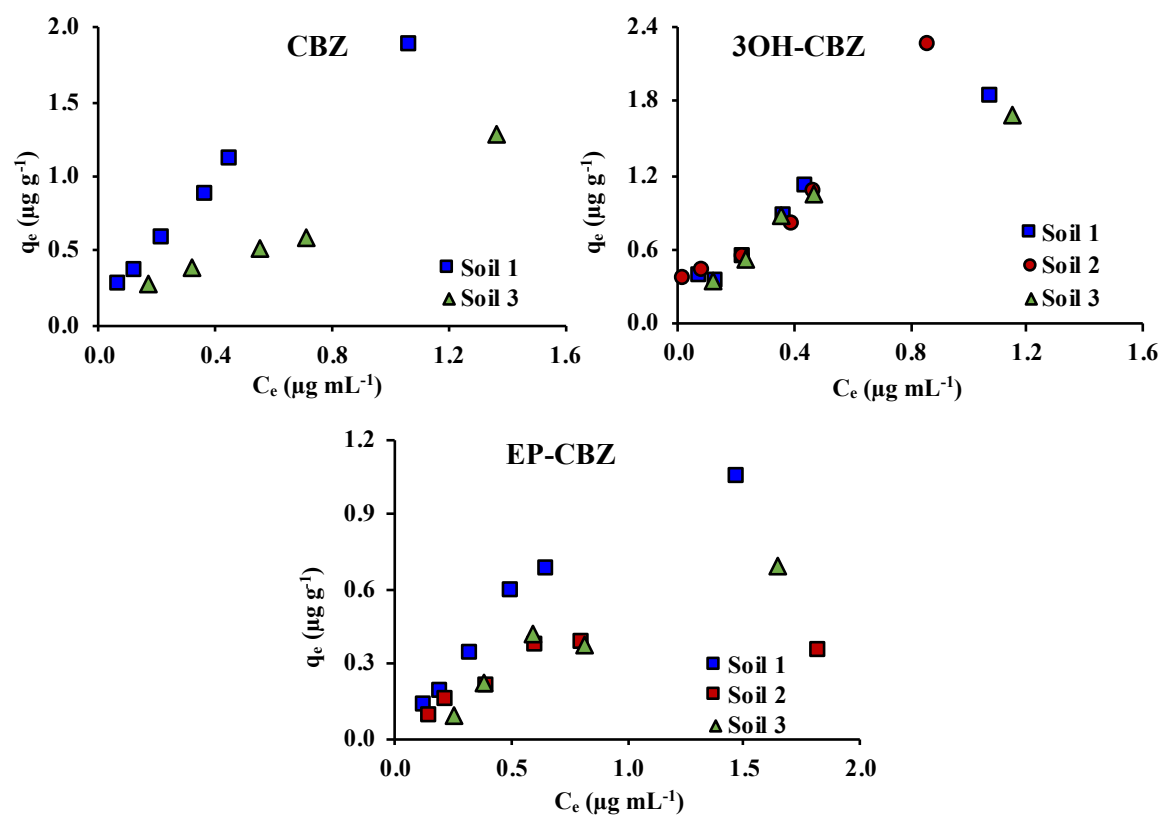

Figure 3. Adsorption curves for $\mathrm{CBZ}$ and its metabolites in studied soils in the four-solute systems; $\mathrm{q}_{\mathrm{e}}$ : amount of compound adsorbed; $\mathrm{C}_{\mathrm{e}}$ : concentration of compound in the equilibrium solution.

A good fitting was obtained for all evaluated isotherms $\left(\mathrm{R}^{2}\right.$ values higher than $0.9100,0.8947$ and 0.8535 for Linear, Freundlich, and Langmuir isotherms models), except in the case of soil 2 for which low correlation coefficients were obtained in the case of Freundlich and Langmuir isotherms of 3OH-CBZ (0.7464 and 0.7501, respectively) and for linear and Freundlich isotherms (0.4900 and 0.8079, respectively) for EP-CBZ. CBZ was not adsorbed in soil 2 and $10 \mathrm{OH}-\mathrm{CBZ}$ was not adsorbed in any of the studied soils.

For most of the studied compounds a decrease of the $\mathrm{K}_{\mathrm{d}}$ and $\mathrm{K}_{\mathrm{F}}$ values was observed, except for CBZ and EP-CBZ in soil 1, which indicates a lower adsorption than those measured in the single-solute experiments. This decrease of the $\mathrm{K}_{\mathrm{d}}$ and $\mathrm{K}_{\mathrm{F}}$ values was especially important in the case of $3 \mathrm{OH}-\mathrm{CBZ}$. For example, in soil 1, $\mathrm{K}_{\mathrm{d}}$ and $\mathrm{K}_{\mathrm{F}}$ values were from 9.89 and 7.12, respectively, to 1.53 and 1.71. Moreover, $1 / \mathrm{n}$ values obtained in four-solute systems were lower than those obtained in single-solute systems. This could indicate the saturation of adsorption sites available to the studied compounds, which results in a lower adsorption. These results could be due to a competition among the studied compounds for active sites of the soils.

\section{Materials and Methods}

\subsection{Chemicals and Reagents}

HPLC-grade methanol $(\mathrm{MeOH})$ and water were supplied by Romil (Barcelona, Spain). Analytical-grade formic acid (98\%) and calcium chloride anhydrous $\left(\mathrm{CaCl}_{2}\right)$ were obtained from Panreac (Barcelona, Spain). CBZ and its metabolites 3OH-CBZ, 10OH-CBZ and EP-CBZ were purchased from Sigma-Aldrich (St. Louis MO, USA). The structural formula and physicochemical properties of these compounds are shown in Table 2. Individual stock standard solutions were prepared at $1000 \mu \mathrm{g} \cdot \mathrm{mL}^{-1}$ in $\mathrm{MeOH}$ and stored at $-18{ }^{\circ} \mathrm{C}$. Working solutions of $100 \mu \mathrm{g} \cdot \mathrm{mL}^{-1}$ were prepared using $0.01 \mathrm{M} \mathrm{CaCl}_{2}$ aqueous solution in order to avoid the co-solvent effect due to a high amount 
of methanol in the adsorption experiments. Other solutions where prepared by dilution of working solution using $0.01 \mathrm{M} \mathrm{CaCl}_{2}$ aqueous solution and stored in dark at $-18{ }^{\circ} \mathrm{C}$.

Table 2. Physical-chemical properties of the target compounds.

\begin{tabular}{|c|c|c|c|c|c|}
\hline Compound & $\begin{array}{l}\text { Molecular } \\
\text { Weight }\end{array}$ & $\mathrm{pK}_{\mathrm{a}}$ & $\begin{array}{l}\log \\
K_{\text {ow }}\end{array}$ & $\begin{array}{c}\text { Water } \\
\text { Solubility } \\
(\mathrm{mg} / \mathrm{L})\end{array}$ & Structure \\
\hline Carbamazepine (CBZ) & 236.27 & $13.9^{a}$ & $2.5^{b}$ & $0.15^{\mathrm{f}}$ & \\
\hline $\begin{array}{l}\text { 3-Hydroxycarbamazepine } \\
\text { (3OH-CBZ) }\end{array}$ & 252.27 & $9.19^{\mathrm{c}}$ & $2.41^{\mathrm{d}}$ & n.a. & \\
\hline $\begin{array}{l}\text { 10,11-Dihydro-10-hydroxy } \\
\text { carbamazepine (10OH-CBZ) }\end{array}$ & 254.28 & $12.8^{\mathrm{d}}$ & $0.93^{\mathrm{e}}$ & n.a. & \\
\hline $\begin{array}{l}\text { Carbamazepine-10,11-epoxide } \\
\text { (EP-CBZ) }\end{array}$ & 252.27 & $16.0^{\mathrm{d}}$ & $1.0^{\mathrm{b}}$ & $1.34^{\mathrm{f}}$ & \\
\hline
\end{tabular}

${ }^{a}$ Rosal et al. 2010 [29]; ${ }^{\mathrm{b}}$ Muñoz et al. 2008 [30]; ${ }^{\mathrm{c}}$ Lee et al. 2011 [31]; ${ }^{\mathrm{d}}$ Huntscha et al. 2012 [32]; ${ }^{\mathrm{e}}$ Miao et al. 2005 [33]; ${ }^{\mathrm{f}}$ Obtained from Human metabolome databases HMDB (http://www.hmdb.ca) (accessed April 2020); n.a.: not available.

\subsection{Sampling and Soil Preparation}

Mediterranean soils with different physicochemical characteristics and widely distributed in Mediterranean region were selected. Soil 1 was an alluvial nature soil sited in the plain of the main rivers from Europe; soils 2 and 3 were terra rossa and cambisol soils and are widely extended in several countries from Europe such as Spain, Italy, Greek, France or Germany.

The three agricultural surface soils $(0-20 \mathrm{~cm})$ were collected from Seville (SW Spain). Soils were freeze-dried in a Cryodos-50 lyophilizer (Telstar, Terrasa, Spain), homogenized, sieved (particle size < $2 \mathrm{~mm}$ ) and kept in glass bottles and stored at $-18^{\circ} \mathrm{C}$.

The characterization of the soils was carried out by the determination of texture (fine sand $(0.2-0.02 \mathrm{~mm})$, coarse sand $(2-0.2 \mathrm{~mm})$, silt $(0.02-0.002)$ and clay (less than 0.002$))$, $\mathrm{pH}$ and electrical conductivity of a 1:2.5 (w/v) soil:water suspension, and organic matter (Walkley-back method). The physicochemical characteristics of the three studied soils are shown in Table 3. The presence of CBZ and its metabolites in the selected soil were investigated by the analysis of the soils according to Malvar et al. (2020) [34]. Concentrations of studied compounds were lower than detection limits in all studied soils. 
Table 3. Physical-chemical properties of the studied Mediterranean soils.

\begin{tabular}{cccc}
\hline & Soil 1 & Soil 2 & Soil 3 \\
\hline Fine sand, wt.\% & 16.4 & 4.70 & 14.0 \\
Coarse sand, wt.\% & 8.20 & 69.5 & 51.6 \\
Silt, wt.\% & 44.5 & 5.80 & 18.4 \\
Clay, wt.\% & 30.8 & 19.9 & 16.0 \\
pH & 8.27 & 8.21 & 8.06 \\
EC, $\mu$ S.cm ${ }^{-1}$ & 129 & 75 & 126 \\
OM, wt.\% & 0.91 & 0.58 & 2.01 \\
\hline
\end{tabular}

EC: Electrical conductivity; OM: organic matter.

\subsection{Batch Experiments}

\subsubsection{Preliminary Experiments}

Adsorption experiments were carried out in triplicate following the OECD guideline 106 [35]. Conditions applied in the all batch experiments are summarized in Table S4 (Supplementary Data). Preliminary tests were carried out in order to obtain the appropriate conditions for the adsorption experiments. Two parameters were evaluated in the preliminary experiments: equilibrium time and soil/solution ratio. The studies reported in the literature about the adsorption of CBZ and related compounds onto the soil were carried out applying an equilibrium time between 18 to $24 \mathrm{~h}[10,17,27]$. In order to obtain the equilibrium time, in this work, this parameter was evaluated in one of the studied soils from $10 \mathrm{~min}$ to $24 \mathrm{~h}$. Soil 1, which showed an adsorption capacity between the other studied soils in previous experiment (data no showed), was selected. A soil/solution ratio of 2:10 (w:v) was applied and a concentration of target compounds of $1 \mu \mathrm{g} \mathrm{mL}-1$ was selected according to adsorption experiment reported in the literature $[10,20,36]$. All experiments were carried out at room temperature $\left(25 \pm 2{ }^{\circ} \mathrm{C}\right)$. For each compound, $2 \mathrm{~g}$ of soil were placed into a $50 \mathrm{~mL}$ falcon centrifuge tube and $9 \mathrm{~mL}$ of $0.01 \mathrm{M} \mathrm{CaCl}_{2}$ solution was added. The mixture was shaken at $40 \mathrm{rpm}$ in a rotator shaker (LLG-uniLOOPMIX2) for $24 \mathrm{~h}$ to pre-equilibrate the soil. Then, $1 \mathrm{~mL}$ of $0.01 \mathrm{M} \mathrm{CaCl}_{2}$ aqueous solution containing $10 \mu \mathrm{g} \cdot \mathrm{mL}^{-1}$ of each tested compound was added. The tubes were agitated at $40 \mathrm{rpm}$ for 10, 20, 30, 40, 50 min and 1, 2, 12, and $24 \mathrm{~h}$. Blank experiments (without soil) were carried out (for $24 \mathrm{~h}$ ) in order to evaluate the potential adsorption of studied compounds into the plastic walls of the falcon tubes and their degradation during batch experiments. All experiments were carried out by triplicate. After agitation, the tubes were centrifuged at $4000 \mathrm{rpm}$ for $10 \mathrm{~min}$. The supernatant was filtered through $0.22 \mu \mathrm{m}$ nylon filter and stored at $-18^{\circ} \mathrm{C}$ until analysis.

The optimal soil/solution ratio was determined for the three studied soils. The appropriate amounts of soil $(1,2,4$, and $5 \mathrm{~g})$, corresponding to $1: 10,2: 10,4: 10$, and $5: 10 \mathrm{soil} /$ solution ratio $(w / v)$, were placed in a falcon centrifuge tube and $9 \mathrm{~mL}$ of $0.01 \mathrm{M} \mathrm{CaCl}_{2}$ solution were added. Ratio values higher than 5:10 $(w / v)$ were not tested in order to avoid the saturation of aqueous solution. Batch experiments were carried out (by triplicate) according to what was described above, including blank experiments and pre-equilibration. Centrifuge tubes were shacked for $24 \mathrm{~h}$ at $40 \mathrm{rpm}$ and then, centrifuged at $4000 \mathrm{rpm}$ for $10 \mathrm{~min}$. The supernatant was filtered at $0.22 \mu \mathrm{m}$ nylon filter and stored at $-18{ }^{\circ} \mathrm{C}$ until analysis.

\subsubsection{Influence of $\mathrm{pH}$ Experiments on the Adsorption of Studied Compounds}

The evaluation of the influence of $\mathrm{pH}$ on the adsorption of studied compounds onto the soil was

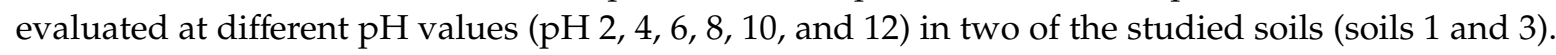
These soils were those where the highest adsorptions were measured in a previous experiments (data no showed). These tests were carried out by triplicate. Batch experiments were done as described in the preliminary experiments section including soil pre-equilibration, blank experiments and shaking 
for $24 \mathrm{~h}$ at $40 \mathrm{rpm}$. The $\mathrm{pH}$ of the aqueous phase was adjusted using $1 \mathrm{M}$ aqueous solutions of $\mathrm{HCl}$ or $1 \mathrm{M}$ aqueous solution of $\mathrm{NaOH}$.

\subsubsection{Adsorption Isotherm Experiments}

For adsorption isotherm experiments, a soil/solution ratio of 5:10 (w:v) and an equilibrium time of $24 \mathrm{~h}$ was selected. The experiments were carried out in triplicate at room temperature $\left(25 \pm 2{ }^{\circ} \mathrm{C}\right)$ for the three studied soils. In addition, control samples (falcon tubes without soil) were processed to evaluate the adsorption of the compounds on the vessels.

Aliquots of $5 \mathrm{~g}$ of soil were placed into a plastic tube and $9 \mathrm{~mL}$ of $0.01 \mathrm{M} \mathrm{CaCl}_{2}$ were added. The tubes were maintained under agitation during $24 \mathrm{~h}$ at $40 \mathrm{rpm}$ to equilibrate the soils. Six different concentrations were used to obtain adsorption isotherms. Each concentration was obtained by the addition of $1 \mathrm{~mL}$ of a working solution containing the proper concentration of the studied compounds. The studied concentrations were $0.2,0.3,0.5,0.8,1$, and $2 \mathrm{mg} \cdot \mathrm{L}^{-1}$ (approximately from 0.8 to $8.5 \mu \mathrm{mol} \cdot \mathrm{L}^{-1}$ for each compound). These concentrations were higher than those usually measured in the environment for these compounds. However, these concentrations were selected considering the concentration ranges used in similar studies reported in the literature for CBZ and its metabolites [20] and for others organic pollutants [27,37]. Moreover, these concentrations were necessary to obtain statistically robust results difficult to obtain at usual environment concentrations. After that, the tubes were agitated for $24 \mathrm{~h}$ at $40 \mathrm{rpm}$, centrifuged for $10 \mathrm{~min}$ at $4000 \mathrm{rpm}$ and filtered through a $0.22 \mu \mathrm{m}$ syringe filter. The described process was applied separately for each target compound (in single-solute experiment) and simultaneously with a mixture of all compounds at the same concentrations (in four-solute experiment).

\subsection{Chromatographic Determination}

Supernatant obtained from preliminary and adsorption isotherms experiments were analyzed by direct injection on LC-MS/MS system according to Malvar et al., 2019 [19]. The equipment used was an Agilent 1200 series HPLC (Agilent, Santa Clara, CA, USA) coupled to a 6410 triple quadrupole (QqQ) mass spectrometer (MS) equipped with an electrospray ionization source (ESI). Chromatographic conditions are summarized in Table S5. MS parameters were as follows: capillary voltage, $4000 \mathrm{~V}$; drying gas flow rate $9 \mathrm{~L} \cdot \mathrm{min}^{-1}$; drying gas temperature $350{ }^{\circ} \mathrm{C}$; and nebulizer pressure; $40 \mathrm{psi}$. Instrument control and data acquisition were carried out with MassHunter software (Agilent, USA). The MS/MS parameters for each compound are given in Table S5 (Supplementary Materials).

\subsection{Method Performance and Quality Control}

The analytical method was validated by the determination of inter- and intraday precision and limit for detection and quantification. Precision was determined by the injection by triplicate of a matrix-matched standard solution at three concentration levels. Limit of detection (LOD) and quantification (LOQ) were determined as the concentration corresponding to signal-to-noise ratios of 3 and 10, respectively. LOD and LOQ were determined by the injection of matrix-matched calibration standards at low concentrations. Inter and intraday precision and limit of detection and quantification are shown in Table S6. The determination of the concentrations was carried out using matrix-matched calibration curves [19]. For this purpose, $5.0 \mathrm{~g}$ of soil was added to a Falcon tube and $9 \mathrm{~mL}$ of $0.01 \mathrm{M}$ $\mathrm{CaCl}_{2}$ solution was added. The tube was shaken for $24 \mathrm{~h}$ at $40 \mathrm{rpm}$. Then, Falcon tube was centrifuged (15 $\mathrm{min}$ at $4000 \mathrm{rpm}$ ) and the supernatant was used for the preparation of the matrix-matched calibration standards.

For each batch of samples, in addition to matrix-matched calibration curves and extracts obtained in batch experiments, quality control standard and blank samples were measured. 


\subsection{Data Analysis}

Adsorption percentage of the compound adsorbed onto the soil was calculated following the expression:

$$
\text { Ads }(\%)=\left[\left(C_{\mathrm{i}}-\mathrm{C}_{\mathrm{e}}\right) / \mathrm{C}_{\mathrm{i}}\right] \times 100
$$

where $C_{i}$ is the initial concentration $\left(\mu \mathrm{g} \mathrm{mL}^{-1}\right)$ and $C_{e}$ is the concentration in the equilibrium $\left(\mu \mathrm{g} \cdot \mathrm{mL}^{-1}\right)$.

The three most widely used models of isotherms were evaluated (Linear, Freundlich and Langmuir). The equilibrium concentration $\left(\mathrm{q}_{\mathrm{e}}, \mu \mathrm{g} \cdot \mathrm{g}^{-1}\right)$ of each tested compound adsorbed onto the soil was calculated as the difference between the solution concentrations before and after the experiment, as follow:

$$
\mathrm{q}_{\mathrm{e}}=\left(\mathrm{C}_{\mathrm{i}}-\mathrm{C}_{\mathrm{e}}\right) \cdot \mathrm{V} / \mathrm{m}
$$

where $\mathrm{Ci}$ is the initial concentration measured in the solution $\left(\mu \mathrm{g} \cdot \mathrm{mL}^{-1}\right), \mathrm{Ce}$ is the concentration measured in the solution in the equilibrium $\left(\mu \mathrm{g} \cdot \mathrm{mL}^{-1}\right), \mathrm{V}$ is the solution volume $(\mathrm{mL})$, and $\mathrm{m}$ is the soil mass (g).

Linear model Equation (3) is the simplest adsorption model and assumes a proportional adsorption. This model can be written as:

$$
\mathrm{q}_{\mathrm{e}}=\mathrm{K}_{\mathrm{d}} \times \mathrm{C}_{\mathrm{e}}
$$

where $K_{d}$ is the solution-soil distribution coefficient $\left(\mathrm{mL} \mathrm{g}^{-1}\right)$.

Freundlich and Langmuir models Equations (4) and (5), respectively, are not linear models and can be expressed as follow:

$$
\begin{gathered}
\mathrm{q}_{\mathrm{e}}=\mathrm{K}_{\mathrm{F}} \times \mathrm{C}_{\mathrm{e}}^{1 / \mathrm{n}} \\
1 / \mathrm{q}_{\mathrm{e}}=1 / \mathrm{q}_{\max }+1 /\left(\mathrm{K}_{\mathrm{L}} \mathrm{q}_{\max } \mathrm{C}_{\mathrm{e}}\right)
\end{gathered}
$$

where $K_{F}$ is the Freundlich coefficient, which is related to the multilayer adsorption capacity $\left(\left(\mu \mathrm{g}^{-} \mathrm{g}^{-1}\right)\right)$ $\left.\left(\mathrm{mL} \cdot \mu \mathrm{g}^{-1}\right)^{1 / \mathrm{n}}\right), \mathrm{K}_{\mathrm{L}}\left(\mathrm{mL} \cdot \mathrm{g}^{-1}\right)$ are Langmuir constants, which are related to the adsorption bonding energy; $1 / \mathrm{n}$ is the heterogeneity factor, which indicates the adsorption intensity; and $\mathrm{q}_{\max }\left(\mu \mathrm{g} \cdot \mathrm{g}^{-1}\right)$ is the maximal adsorption capacity.

All models were fitted using Excel and applying the correlation coefficient $\left(R^{2}\right)$ to judge the fitting goodness of different models to data.

Statistical techniques, correlation, and factor analysis were used to evaluate the existence of potential correlations between the adsorption of studied compounds and the characteristics of the studied soils. For this purpose, the mean adsorption of each studied compound and the physicochemical characteristics of the soils (Table 3) were used as variables and each of the soils as cases. Statistical analysis was carried out using Statistical 10.0 software for Windows.

\section{Conclusions}

In this work, the adsorption of CBZ and its main metabolites in three Mediterranean soils have been studied in single-solute and four-solute systems. The adsorptions measured in the soils were in the order: $3 \mathrm{OH}-\mathrm{CBZ}>\mathrm{CBZ}>\mathrm{EP}-\mathrm{CBZ}>10 \mathrm{OH}-\mathrm{CBZ}$. This could be explained considering the functional groups of the compounds and their position in the molecules. The adsorption of $3 \mathrm{OH}-\mathrm{CBZ}$ on the soils was strongly affected by the $\mathrm{pH}$ of the aqueous solution. In the case of the other studied compounds, low influence was observed, mainly due to their $\mathrm{pK}_{\mathrm{a}}$ values.

The influence of physicochemical characteristics of the soils on the adsorption of the target compounds was evaluated in both single-solute and four-solute experiments. Considering single-solute systems, a high correlation was obtained between the adsorption of CBZ and EP-CBZ and the organic matter of the soil. However, in the case of hydroxylated compounds (3OH-CBZ and 10OH-CBZ), the high correlation was measured between their adsorptions and the texture of the soils. Moreover, a good fit was measured in all studied adsorption isotherms in the single-solute experiments. These 
could be related with the low concentration ranges evaluated and the excess of active sites in the studied soils.

A decrease of the adsorption of CBZ and its metabolites was observed in the four-solute experiments. Moreover, in spite of the good fit observed in the isotherms evaluated, this fit was, in most of the cases, lower than those observed in the single-solute experiments. Moreover, the study of the adsorption isotherms showed the saturation of adsorption sites available to the studied compounds. These results could be due to the competition between the studied compounds, and a higher influence of the texture of the soil was observed.

The results obtained in this work show the importance of evaluating adsorption behaviour of the studied compounds in the complex real environments as soils amended with compost or sludge from wastewater treatment plants or even irrigated with treated wastewater.

Supplementary Materials: The following are available online. Figure S1. Evaluation of the equilibrium time on the sorption of CBZ, 3OH-CBZ, 10OH-CBZ, and EP-CBZ onto the soil; Figure S2. Evaluation of the soil/solution ratio on the sorption of $\mathrm{CBZ}, 3 \mathrm{OH}-\mathrm{CBZ}, 10 \mathrm{OH}-\mathrm{CBZ}$, and $\mathrm{EP}-\mathrm{CBZ}$ onto the soil; Figure S3. Evaluation of the influence of $\mathrm{pH}$ on the sorption of $\mathrm{CBZ}, 3 \mathrm{OH}-\mathrm{CBZ}, 10 \mathrm{OH}-\mathrm{CBZ}$, and $\mathrm{EP}-\mathrm{CBZ}$ onto (A) soil 1 and (B) soil 3; Figure S4. Linear, Freundlich and Langmuir models of CBZ adsorption on soil 1 in single-solute and four-solute systems; Figure S5. Linear, Freundlich and Langmuir models of CBZ adsorption on soil 3 in single-solute and four-solute systems; Figure S6. Linear, Freundlich and Langmuir models of 3OH-CBZ adsorption on soil 1 in single-solute and four-solute systems; Figure S7. Linear, Freundlich and Langmuir models of $3 \mathrm{OH}-\mathrm{CBZ}$ adsorption on soil 2 in single-solute and four-solute systems; Figure S8. Linear, Freundlich and Langmuir models of 3OH-CBZ adsorption on soil 3 in single-solute and four-solute systems; Figure S9. Linear, Freundlich and Langmuir models of $10 \mathrm{OH}-\mathrm{CBZ}$ adsorption on soil 1 in the single-solute system; Figure S10. Linear, Freundlich and Langmuir models of 10OH-CBZ adsorption on soil 3 in the single-solute system; Figure S11. Linear, Freundlich and Langmuir models of EP-CBZ adsorption on soil 1 in single-solute and four-solute systems; Figure S12. Linear, Freundlich and Langmuir models of EP-CBZ adsorption on soil 2 in single-solute and four-solute systems; Figure S13. Linear, Freundlich and Langmuir models of EP-CBZ adsorption on soil 3 in single-solute and four-solute systems (Table S1). Matrix correlation of CBZ, 3-OH CBZ, 10-OH CBZ and EP-CBZ in single and four solute systems, texture soils, organic matter and organic carbon; Table S2. Results of the factorial analysis considering adsorption of studied compounds in the single-solute experiments and the physicochemical characteristics of the soils as variables and soils as cases; Table S3. Results of the factorial analysis considering adsorption of studied compounds in the four-solute experiments and the physicochemical characteristics of the soils as variables and soils as cases; Table S4. Conditions applied in the batch experiments; Table S5. LC-MS/MS parameters (Table S6). Instrumental limits of detection (LOD), instrumental limits of quantitation (LOQ) and intra- and interday precision, measured as relative standard deviation $(n=3)$ of the optimized methods.

Author Contributions: Investigation, Resources, J.L.M.; Conceptualization, Writing-original draft, J.L.S.; Methodology, Formal analysis, J.M.; Validation, Writing-review \& editing, I.A.; Conceptualization, Supervision, Project administration, Funding acquisition, E.A. All authors have read and agreed to the published version of the manuscript.

Funding: This work was financially supported by the Spanish Ministry of Economy and Competitiveness (Project No. CTM2017-82778-R).

Acknowledgments: J.L. Malvar gratefully acknowledges FPU programme from Spanish Government for his pre-doctoral contract (FPU17/00368).

Conflicts of Interest: The authors declare no conflict of interest.

\section{References}

1. Boix, C.; Ibáñez, M.; Zamora, T.; Sancho, J.; Niessen, W.; Hernández, F. Identification of new omeprazole metabolites in wastewaters and surface waters. Sci. Total Environ. 2014, 468-469, 706-714. [CrossRef] [PubMed]

2. Ferrando-Climent, L.; Collado, N.; Buttiglieri, G.; Gros, M.; Layret, I.R.-R.; Rodríguez-Mozaz, S.; Barceló, J. Comprehensive study of ibuprofen and its metabolites in activated sludge batch experiments and aquatic environment. Sci. Total Environ. 2012, 438, 404-413. [CrossRef] [PubMed]

3. He, K.; Yonetani, T.; Asada, Y.; Echigo, S.; Itoh, S. Simultaneous determination of carbamazepine-N-glucuronide and carbamazepine phase I metabolites in the wastewater by liquid chromatography-tandem mass spectrometry. Microchem. J. 2019, 145, 1191-1198. [CrossRef] 
4. Cao, S.-S.; Duan, Y.; Tu, Y.-J.; Tang, Y.; Liu, J.; Zhi, W.-D.; Dai, C. Pharmaceuticals and personal care products in a drinking water resource of Yangtze River Delta Ecology and Greenery Integration Development Demonstration Zone in China: Occurrence and human health risk assessment. Sci. Total Environ. 2020, 721, 137624. [CrossRef] [PubMed]

5. García-Galán, M.J.; Díaz-Cruz, M.S.; Barceló, J. Multiresidue trace analysis of sulfonamide antibiotics and their metabolites in soils and sewage sludge by pressurized liquid extraction followed by liquid chromatography-electrospray-quadrupole linear ion trap mass spectrometry. J. Chromatogr. A 2013, 1275, 32-40. [CrossRef] [PubMed]

6. Peysson, W.; Vulliet, E. Determination of 136 pharmaceuticals and hormones in sewage sludge using quick, easy, cheap, effective, rugged and safe extraction followed by analysis with liquid chromatography-time-of-flight-mass spectrometry. J. Chromatogr. A 2013, 1290, 46-61. [CrossRef]

7. Rossini, D.; Ciofi, L.; Ancillotti, C.; Checchini, L.; Bruzzoniti, M.; Rivoira, L.; Fibbi, D.; Orlandini, S.; Del Bubba, M. Innovative combination of QuEChERS extraction with on-line solid-phase extract purification and pre-concentration, followed by liquid chromatography-tandem mass spectrometry for the determination of non-steroidal anti-inflammatory drugs and their metabolites in sewage sludge. Anal. Chim. Acta 2016, 935, 269-281.

8. Wu, C.; Pongberg, A.L.S.; Itter, J.D.W.; Ang, M.F.; Zajkowski, K.P.C. Uptake of Pharmaceutical and Personal Care Products by Soybean Plants from Soils Applied with Biosolids and Irrigated with Contaminated Water. Environ. Sci. Technol. 2010, 44, 6157-6161. [CrossRef]

9. Milieu Ltd.; WRc; RPA. Environmental, Economic and Social Impacts of the Use of Sewage Sludge on Land. Final Report Part I: Overview Report 2008. Available online: http://ec.europa.eu/environment/archives/ waste/sludge/pdf/part_i_report.pdf (accessed on 12 November 2020).

10. Kočárek, M.; Kodešová, R.; Vondráčková, L.; Golovko, O.; Fér, M.; Klement, A.; Nikodem, A.; Jakšík, O.; Grabic, R. Simultaneous sorption of four ionizable pharmaceuticals in different horizons of three soil types. Environ. Pollut. 2016, 218, 563-573. [CrossRef]

11. Biel-Maeso, M.; González-González, C.; Lara-Martín, P.A.; Corada-Fernández, C. Sorption and degradation of contaminants of emerging concern in soils under aerobic and anaerobic conditions. Sci. Total Environ. 2019, 666, 662-671. [CrossRef]

12. Yu, C.; Bi, E. Adsorption site-dependent transport of diclofenac in water saturated minerals and reference soils. Chemosphere 2019, 236, 124256. [CrossRef] [PubMed]

13. Jung, C.; Boateng, L.K.; Flora, J.R.; Oh, J.; Braswell, M.C.; Son, A.; Yoon, Y. Competitive adsorption of selected non-steroidal anti-inflammatory drugs on activated biochars: Experimental and molecular modeling study. Chem. Eng. J. 2015, 264, 1-9. [CrossRef]

14. Lerman, I.; Chen, Y.; Xing, B.; Chefetz, B. Adsorption of carbamazepine by carbon nanotubes: Effects of DOM introduction and competition with phenanthrene and bisphenol A. Environ. Pollut. 2013, 182, 169-176. [CrossRef] [PubMed]

15. Kaserzon, S.L.; Vermeirssen, E.L.M.; Hawker, D.W.; Kennedy, K.; Bentley, C.; Thompson, J.; Booij, K.; Mueller, J. Passive sampling of perfluorinated chemicals in water: Flow rate effects on chemical uptake. Environ. Pollut. 2013, 177, 58-63. [CrossRef]

16. Orta, M.D.M.; Martín, J.; Medina-Carrasco, S.; Santos, J.L.; Aparicio, I.; Alonso, E. Adsorption of propranolol onto montmorillonite: Kinetic, isotherm and pH studies. Appl. Clay Sci. 2019, 173, 107-114. [CrossRef]

17. Fenet, H.; Mathieu, O.; Mahjoub, O.; Li, Z.; Hillaire-Buys, D.; Casellas, C.; Gomez, E. Carbamazepine, carbamazepine epoxide and dihydroxycarbamazepine sorption to soil and occurrence in a wastewater reuse site in Tunisia. Chemosphere 2012, 88, 49-54. [CrossRef]

18. Leclercq, M.; Mathieu, O.; Gomez, E.; Casellas, C.; Fenet, H.; Hillaire-Buys, D. Presence and Fate of Carbamazepine, Oxcarbazepine, and Seven of Their Metabolites at Wastewater Treatment Plants. Arch. Environ. Contam. Toxicol. 2009, 56, 408-415. [CrossRef]

19. Malvar, J.L.; Santos, J.L.; Martín, J.; Aparicio, I.; Alonso, E. Routine analytical method for monitoring the main metabolites for a recurrent group of parabens and pharmaceuticals in wastewater and tap water. Anal. Bioanal. Chem. 2019, 411, 6625-6635. [CrossRef] 
20. Wojsławski, J.; Białk-Bielińska, A.; Stepnowski, P.; Dołżonek, J. Leaching behavior of pharmaceuticals and their metabolites in the soil environment. Chemosphere 2019, 231, 269-275. [CrossRef]

21. Bahlmann, A.; Brack, W.; Schneider, R.J.; Krauss, M. Carbamazepine and its metabolites in wastewater: Analytical pitfalls and occurrence in Germany and Portugal. Water Res. 2014, 57, 104-114. [CrossRef]

22. Kodešová, R.; Klement, A.; Golovko, O.; Fér, M.; Kočárek, M.; Nikodem, A.; Grabic, R. Soil influences on uptake and transfer of pharmaceuticals from sewage sludge amended soils to spinach. J. Environ. Manag. 2019, 250, 109407. [CrossRef] [PubMed]

23. Paz, A.; Tadmor, G.; Malchi, T.; Blotevogel, J.; Borch, T.; Polubesova, T.; Chefetz, B. Fate of carbamazepine, its metabolites, and lamotrigine in soils irrigated with reclaimed wastewater: Sorption, leaching and plant uptake. Chemosphere 2016, 160, 22-29. [CrossRef] [PubMed]

24. Gros, M.; Mas-Pla, J.; Boy-Roura, M.; Geli, I.; Domingo, F.; Petrović, M. Veterinary pharmaceuticals and antibiotics in manure and slurry and their fate in amended agricultural soils: Findings from an experimental field site (Baix Empordà, NE Catalonia). Sci. Total Environ. 2019, 654, 1337-1349. [CrossRef] [PubMed]

25. Conde-Cid, M.; Nóvoa-Muñoz, J.; Fernández-Sanjurjo, M.; Núñez-Delgado, A.; Álvarez-Rodríguez, E.; Arias-Estévez, M. Pedotransfer functions to estimate the adsorption and desorption of sulfadiazine in agricultural soils. Sci. Total Environ. 2019, 691, 933-942. [CrossRef] [PubMed]

26. Giles, C.H.; MacEwan, T.H.; Nakhwa, S.N.; Smith, D. 786. Studies in adsorption. Part XI. A system of classification of solution adsorption isotherms, and its use in diagnosis of adsorption mechanisms and in measurement of specific surface areas of solids. J. Chem. Soc. 1960, 4, 3973-3993. [CrossRef]

27. Pavlović, D.M.; Glavač, A.; Gluhak, M.; Runje, M. Sorption of albendazole in sediments and soils: Isotherms and kinetics. Chemosphere 2018, 193, 635-644. [CrossRef] [PubMed]

28. Evers, D.C.; Keane, S.E.; Basu, N.; Buck, D. Evaluating the effectiveness of the Minamata Convention on Mercury: Principles and recommendations for next steps. Sci. Total Environ. 2016, 323, 888-903. [CrossRef] [PubMed]

29. Rosal, R.; Rodríguez, A.; Perdigón-Melón, J.A.; Petre, A.; García-Calvo, E.; Gómez, M.J.; Agüera, A.; Fernández-Alba, A.R. Occurrence of emerging pollutants in urban wastewater and their removal through biological treatment followed by ozonation. Water Res. 2010, 44, 578-588. [CrossRef] [PubMed]

30. Muñoz, I.; Gómez, M.J.; Molina-Díaz, A.; Huijbregts, M.A.; Fernández-Alba, A.R.; García-Calvo, E. Ranking potential impacts of priority and emerging pollutants in urban wastewater through life cycle impact assessment. Chemosphere 2008, 74, 37-44. [CrossRef]

31. Lee, S.; Kang, S.-I.; Lim, J.-L.; Huh, Y.J.; Kim, K.-S.; Cho, J. Evaluating controllability of pharmaceuticals and metabolites in biologically engineered processes, using corresponding octanol-water distribution coefficient. Ecol. Eng. 2011, 37, 1595-1600. [CrossRef]

32. Huntscha, S.; Singer, H.P.; McArdell, C.S.; Frank, C.E.; Hollender, J. Multiresidue analysis of 88 polar organic micropollutants in ground, surface and wastewater using online mixed-bed multilayer solid-phase extraction coupled to high performance liquid chromatography-tandem mass spectrometry. J. Chromatogr. A 2012, 1268, 74-83. [CrossRef] [PubMed]

33. Miao, X.-S.; Yang, J.-J.; Metcalfe, C.D. Carbamazepine and Its Metabolites in Wastewater and in Biosolids in a Municipal Wastewater Treatment Plant. Environ. Sci. Technol. 2005, 39, 7469-7475. [CrossRef] [PubMed]

34. Malvar, J.L.; Santos, J.L.; Martín, J.; Aparicio, I.; Alonso, E. Simultaneous pressurized liquid extraction and clean-up for the determination of metabolites in complex environmental solid matrices. Microchem. J. 2020, 152, 104370. [CrossRef]

35. OECD. Adsorption-Desorption Using a Batch Equilibrium Method. OECD Guideline for the Testing of Chemicals; Organization for Economic Cooperation and Development: Paris, France, 2000; Volume 106.

36. Kiecak, A.; Sassine, L.; Boy-Roura, M.; Elsner, M.; Mas-Pla, J.; Salle, C.L.G.L.; Stumpp, C. Sorption properties and behaviour at laboratory scale of selected pharmaceuticals using batch experiments. J. Contam. Hydrol. 2019, 225, 103500. [CrossRef] [PubMed] 
37. Mrozik, W.; Stefanska, J. Adsorption and biodegradation of antidiabetic pharmaceuticals in soils. Chemosphere 2014, 95, 281-288. [CrossRef] [PubMed]

Sample Availability: Samples of the compounds are available from the authors.

Publisher's Note: MDPI stays neutral with regard to jurisdictional claims in published maps and institutional affiliations.

(C) 2020 by the authors. Licensee MDPI, Basel, Switzerland. This article is an open access article distributed under the terms and conditions of the Creative Commons Attribution (CC BY) license (http://creativecommons.org/licenses/by/4.0/). 